\title{
White matter microstructure in 22q11 deletion syndrome: a pilot diffusion tensor imaging and voxel-based morphometry study of children and adolescents
}

\author{
Frederick Sundram • Linda E. Campbell • Rayna Azuma • Eileen Daly • \\ Oswald J. N. Bloemen • Gareth J. Barker • Xavier Chitnis • Derek K. Jones • \\ Therese van Amelsvoort • Kieran C. Murphy • Declan G. M. Murphy
}

Received: 5 December 2009 /Accepted: 5 February 2010/Published online: 5 March 2010

(C) Springer Science+Business Media, LLC 2010

\begin{abstract}
Young people with 22q11 Deletion Syndrome (22q11DS) are at substantial risk for developing psychosis and have significant differences in white matter (WM) volume. However, there are few in vivo studies of both WM microstructural integrity (as measured using Diffusion Tensor (DT)-MRI) and WM volume in the same individual. We used DT-MRI and structural MRI (sMRI) with voxel
\end{abstract}

F. Sundram $(\bowtie) \cdot$ E. Daly • O. J. N. Bloemen · D. G. M. Murphy Section of Brain Maturation, Division of Psychological Medicine, Institute of Psychiatry, King's College London,

PO Box 50, De Crespigny Park,

London SE5 8AF, UK

e-mail: Fred.Sundram@kcl.ac.uk

\section{E. Campbell}

Centre for Brain \& Mental Health Research,

University of Newcastle,

Newcastle, Australia

R. Azuma

Waseda University,

Tokyo, Japan

G. J. Barker $\cdot X$. Chitnis

Centre for Neuroimaging Sciences, Department of Clinical

Neuroscience, Institute of Psychiatry, King's College London,

London, UK

\section{K. Jones}

Cardiff University Brain Research Imaging Centre (CUBRIC),

School of Psychology, Cardiff University,

Cardiff, UK

T. van Amelsvoort

Department of Psychiatry, Academic Medical Center,

Amsterdam, The Netherlands

F. Sundram $\cdot$ K. C. Murphy

Department of Psychiatry, Royal College of Surgeons in Ireland, Dublin, Ireland based morphometry (VBM) to compare, respectively, the fractional anisotropy (FA) and WM volume of 11 children and adolescents with 22q11DS and 12 controls. Also, within 22q11DS we related differences in WM to severity of schizotypy, and polymorphism of the catechol-Omethyltransferase (COMT) gene. People with 22q11DS had significantly lower FA in inter-hemispheric and brainstem and frontal, parietal and temporal lobe regions after covarying for IQ. Significant WM volumetric increases were found in the internal capsule, anterior brainstem and frontal and occipital lobes. There was a significant negative correlation between increased schizotypy scores and reduced WM FA in the right posterior limb of internal capsule and the right body and left splenium of corpus callosum. Finally, the Val allele of COMT was associated with a significant reduction in both FA and volume of WM in the frontal lobes, cingulum and corpus callosum. Young people with 22q11DS have significant differences in both WM microstructure and volume. Also, there is preliminary evidence that within 22q11DS, some regional differences in FA are associated with allelic variation in COMT and may perhaps also be associated with schizotypy.

Keywords 22q11DS · VCFS · COMT · DTI - VBM · Psychosis

\section{Introduction}

22q11 Deletion Syndrome (22q11DS) is the most frequent human genetic deletion syndrome (Gothelf and Lombroso 2001) with an approximate incidence of 1 per 4,000 live births (Oskarsdottir et al. 2004). People with 22q11DS have 
a deletion at chromosome $22 \mathrm{q} 11.2$ which is associated with a phenotype that includes physical, behavioural, psychiatric and neuropsychological anomalies (Swillen et al. 1999; Feinstein and Eliez 2000). Characteristic physical features of 22q11DS include facial dysmorphology and palatal defects, cardiac anomalies and thymic hypoplasia (Goodman 2003). People with 22q11DS are also reported to have an increased incidence of neuroanatomical abnormalities.

Such neuroanatomical differences include midline anomalies (e.g. white matter (WM) hyperintensities and septum pellucidum defects (Mitnick et al. 1994; van Amelsvoort et al. 2001; Campbell et al. 2006) and cortical dysgenesis such as polymicrogyria (Robin et al. 2006). In children and adolescents with the disorder, a significant reduction in volume of posterior brain structures (especially in the cerebellum, temporal and parietal lobes) is largely accounted for by decreased WM volume (Eliez et al. 2000; Kates et al. 2001; Campbell et al. 2006). 22q11DS children are also reported to have a significant reduction in WM content of the frontal lobe, cerebellum and internal capsule as compared to their healthy sibling controls (Campbell et al. 2006).

Thus, there is increasing evidence that children and adolescents with 22q11DS have regionally specific differences in brain anatomy, and perhaps especially affecting WM. If so, this suggests that differences in both brain 'connectivity' and in the microstructure of WM occurs in 22q11DS (Kiehl et al. 2008). Hence interest has recently turned to investigating abnormalities in the 'connectivity' of neural systems using proxy measures of microstructural integrity acquired using Diffusion Tensor MRI (DT-MRI) (Basser et al. 1994a).

DT-MRI permits assessment of WM through a directional dependence of diffusion of water molecules termed anisotropy, which is usually quantified through the calculation of fractional anisotropy (FA) (Pierpaoli and Basser 1996). In the first DT-MRI study of 22q11DS (Barnea-Goraly et al. 2003), significantly reduced FA of WM was reported in frontal, parietal and temporal regions of the 22q11DS subject group which included children, adolescents and adults with the disorder. Additionally, FA deficits were also reported in WM tracts connecting the frontal and temporal lobes of the same group. This study was a valuable first step. However, both adults and children were combined as one group, and most of the cerebellum and brainstem was excluded from analysis.

A subsequent study using DT-MRI only involving 22q11DS children and adolescents (Simon et al. 2005) reported decreased FA in the corpus callosum of 22q11DS subjects but increased FA in the cingulum and right inferior parietal lobule of the same group. The authors postulated a posteriorly displaced corpus callosum in young people with 22q11DS to account for their findings; however, a healthy paediatric brain template was used for spatial normalisation in this study which is a potential cause of mis-registration. Given that the cerebellum and posterior brain structures have been previously implicated in volumetric MRI studies of 22q11DS, and that age and choice of brain template may affect measures of brain anatomy, we wished to examine WM anatomy in a relatively homogeneous group of children and adolescents with no clinically detectable comorbid psychiatric disorder, to include the cerebellum and brainstem, and to determine if differences in WM FA overlap with those in WM volume as assessed by VBM.

As supra-regional brain systems often share common developmental influences (Cheverud 1984), 22q11DS also allows us to examine the modulatory effect of a number of candidate genes located at 22q11.2. One of these is the gene for catechol-O-methyltransferase (COMT), an enzyme that degrades dopamine, which in turn modulates brain development and function (Hoglinger et al. 2004; Zinkstok et al. 2006). The COMT gene undergoes a naturally occurring polymorphism which has been reported to affect dopamine regulation (Akil et al. 2003); the polymorphism leads to an amino acid substitution (Valine[Val] to Methionine[Met]) and results in decreased thermostability and variable enzymatic activity. The Met/Met variant of COMT displays approximately $40 \%$ less enzymatic activity than $\mathrm{Val} / \mathrm{Val}$ (Chen et al. 2004). COMT may influence WM integrity through the regulation of dopamine levels, which in turn can further modulate the proliferation and differentiation of oligodendrocytes and thus affect the formation of myelin (Bongarzone et al. 1998). More recently, COMT Val158Met polymorphism has been found to affect the association between IQ and white matter architecture in the prefrontal lobe and hippocampal formation ( $\mathrm{Li}$ et al. 2009). However, as a consequence of chromosomal deletions, 22q11DS individuals possess only one working copy of the COMT gene (i.e. they are haploinsufficient) which results in either a high activity Val $\left({ }^{\mathrm{V}} \mathrm{COMT}\right)$ or low activity Met $\left({ }^{\mathrm{M}} \mathrm{COMT}\right)$ isoform of the COMT enzyme. Disrupted dopaminergic modulation and neurotransmission may occur as a result of haploinsufficiency and has been reported in adults with 22q11DS without a psychiatric history (Boot et al. 2008) which may explain their vulnerability for the development of psychiatric disorders.

The very high prevalence of psychiatric disorders in 22q11DS is likely to be caused by haploinsufficiency of one or more genes deleted on 22q11.2 and subsequent differences in brain structure, cerebral maturation and neurotransmitter systems. Schizophrenia spectrum disorders are especially prevalent in young adults with 22q11DS (Murphy et al. 1999; Murphy 2002) and through the assessment of schizophrenia and related disorders such as schizotypy, 22q11DS provides a unique neurobiological template for understanding the evolution of psychosis 
(Murphy and Owen 2001). Schizotypy is significantly increased in both 22q11DS children and adults (Murphy et al. 1999; Baker and Skuse 2005) and when present in childhood (both deleted and non-deleted populations), it confers greater susceptibility to the development of psychosis in later life (Chapman et al. 1994; Poulton et al. 2000; Siever and Davis 2004). Given that WM structure is significantly affected in 22q11DS and WM integrity abnormalities have been related to schizotypy in the non-deleted population (Nakamura et al. 2005), we wished to examine for the first time if similar disruption occurs in 22q11DS.

In summary, there is mounting evidence that children and adolescents with 22q11DS may have significant differences in the development and 'connectivity' of specific brain regions; however relatively few studies have directly examined the anatomy and microstructural integrity of WM in a young cohort with the disorder. Further, COMT polymorphism may modulate brain maturation through dopamine metabolism but its effect on WM integrity has been relatively understudied in children and adolescents with 22q11DS. Also, given the high rates of schizophrenia spectrum disorders reported in 22qDS adults and schizotypy being a risk factor in children for the future development of psychosis, we wished to assess WM changes associated with schizotypy in a young 22q11DS population at risk of developing psychosis. Therefore we tested the main hypothesis that children and adolescents with 22q11DS have significant differences from controls in WM microstructural integrity and WM volume. Also, we carried out preliminary post hoc investigations to test additional hypotheses that, within young people with 22q11DS, (1) severity of schizotypy is correlated with differences in WM integrity; and (2) polymorphism of the COMT gene is associated with differences in WM volume and coherence.

\section{Method}

\section{Subjects}

As part of our group's longitudinal work into 22q11DS, we have recruited subjects from the 22qDS support group (UK) and the Behavioural Genetics Clinic at the South London and Maudsley NHS Foundation Trust. Thirty-nine children and adolescents with 22q11DS have previously had a structural MRI scan (Campbell et al. 2006) of which, 12 successfully underwent DT-MRI at the same scanning session which forms the focus of the current study.

All participants were medication free, had English as their first language, and were right handed as assessed by the Annett Handedness Questionnaire. The study was approved by the Ethics Committee at the Institute of Psychiatry, London (IoP). Written informed consent was obtained from carers, and assent from children, after full description of the study.

As a DT-MRI scan for one 22q11DS subject demonstrated excessive motion artefact, his scans were excluded from further analysis. We therefore included 11 young people (five male and six female) with clinical features of 22q11DS and an established genetic 22q11.2 deletion (mean age: 12 years, $\mathrm{SD} \pm 2.2$, range 9-17 years; mean FSIQ: $66, \mathrm{SD} \pm 8.0$, range $56-84$ ). Exclusion criteria were a 22q11DS clinical phenotype but without the large $3 \mathrm{Mb}$ 22q11.2 deletion, a clinically detectable medical disorder known to affect brain structure (e.g. epilepsy), a history of head injury or contraindications to MRI scanning.

22q11DS cases were compared to 12 healthy controls (eight male and four female) with a non-deleted 22q11.2 region (mean age: 13 years, $\mathrm{SD} \pm 3$, range 9-17 years; mean FSIQ: $116, \mathrm{SD} \pm 16$, range 90-141). In contrast to our previous structural MRI work using only sibling controls (Campbell et al. 2006), controls in this study were a combination of sibling $(n=7)$ and non-sibling $(n=5)$ controls. All healthy controls were free from genetic and physical disorders affecting brain anatomy or function. See Table 1.

\section{Medical and psychiatric disorders}

Children and parents were examined through semistructured interview to evaluate past medical history and all subjects had a detailed physical examination. We obtained copies of past assessments from their local health services. Controls were free from medical illness while 22q11DS subjects (as expected) had a range of palatal $(n=$ $9)$ and cardiac/vascular anomalies $(n=6)$.

The Wechsler Intelligence Scale for Children-III (WISCIII) (Wechsler 1991) was used to assess general intellectual functioning while the strengths and difficulties questionnaire (SDQ) (Goodman et al. 2000) measured emotional symptoms, hyperactivity/inattention, conduct problems, peer problems and pro-social behaviour in all subjects. The autism screening questionnaire (ASQ) (short-version) (Berument et al. 1999) was used to measure autistic symptoms with a cut-off score of 7 for individuals who may have autism.

We used a previously published schizotypy scale designed for young people with 22q11DS (Campbell et al. 2006) and all behavioural assessments were completed by a primary caregiver or parents. Also, due to the high incidence of co-morbid neuropsychiatric disorder in 22q11DS and the potential for non-homogeneity, we only recruited subjects that were free (as far as we could best determine) from Axis One psychiatric disorder. 
Table 1 Demographic, genetic and behavioural data and global volume

\begin{tabular}{|c|c|c|c|}
\hline & 22q11DS $(n=11)$ & Controls $(n=12)$ & P-value \\
\hline Gender male/female & $5 / 6$ & $8 / 4$ & $1.0,0.39$ \\
\hline Mean Age & 12 (SD \pm 2.2 ; Range: 9-17) & 13 (SD \pm 2.5 ; Range: 9-17) & 0.83 \\
\hline Mean FSIQ & 66 (SD \pm 8.0 ; Range: $56-84)$ & 116 (SD \pm 15.9 ; Range: 90-141) & $<0.001$ \\
\hline Handedness & 11 Right & 12 Right & - \\
\hline Strengths and Difficulties Questionnaire mean total score & $15.2(\mathrm{SD} \pm 7.1$; Range: $6-25)$ & $4.9(\mathrm{SD} \pm 3.4$; Range: $0-11)$ & 0.002 \\
\hline Schizotypy mean score & $2.0(\mathrm{SD} \pm 2.3$; Range: $0-7)$ & 0 (SD \pm 0 ; Range: 0$)$ & 0.034 \\
\hline Autism Screening Questionnaire mean score & $6.8(\mathrm{SD} \pm 4.3$; Range: $0-13)$ & $2(\mathrm{SD} \pm 4.0$; Range: $0-10)$ & 0.044 \\
\hline COMT status & $7^{\mathrm{V}}$ COMT vs. $4{ }^{\mathrm{M}}$ COMT & - & 0.549 \\
\hline Mean global grey matter volume $(\mathrm{ml})$ & 738 (SD \pm 69.1 ; Range: 649-814) & 790 (SD \pm 59.0 ; Range: 692-896) & 0.067 \\
\hline Mean global white matter volume $(\mathrm{ml})$ & 385 (SD \pm 36.5 ; Range: $321-436)$ & 418 (SD \pm 62.2 ; Range: $327-512)$ & 0.138 \\
\hline Mean total brain volume (ml) & 1122 (SD \pm 97.8 ; Range: 975-1234) & $1207(\mathrm{SD} \pm 108.3$; Range: $1018-1408)$ & 0.062 \\
\hline
\end{tabular}

\section{Genetics}

DNA was extracted from blood samples collected on all subjects. Fluorescence in situ hybridisation (FISH) (Oncor Inc, Gaithersburg, MD, USA) confirmed $3 \mathrm{Mb} 22 \mathrm{q} 11.2$ deletion in 22q11DS cases while chromosome 22q11.2 deletion was excluded in all controls. The COMT $\mathrm{Val}^{158} \mathrm{Met}$ polymorphism was genotyped using the SNaPshot technique of single base extension (Applied Biosystems, Foster City, CA, USA). The initial PCR reaction was performed using a Touchdown-PCR-protocol, with the following primers: forward: 5'-ACTGTGGCTACTCAGCTGTG-3' and reverse: 5'-CCTTTTTCCAGGTCTGACAA-3'. The allele at the single nucleotide polymorphism (SNP) position was determined by use of a $30 \mathrm{bp}$ extension primer (5'-ATCACC CAGCGGATGGTGGATTTCGCTGGC-3'). All alleles were resolved on an ABI 3100 sequencer (Applied Biosystems, Foster City, CA, USA).

\section{MRI acquisition protocol}

Data were acquired using a 1.5 T GE Signa LX system (General Electric, Milwaukee, WI, USA), with actively shielded magnetic field gradients (maximum amplitude $40 \mathrm{mT} \mathrm{m}^{-1}$ ). A standard quadrature birdcage head coil was used for both RF transmission and signal reception. Each DT-MRI volume was acquired using a multi-slice peripherally-gated echo-planar imaging (EPI) sequence, optimised for precise measurement of the diffusion tensor in brain parenchyma, from 60 contiguous near-axial slice locations. Images were acquired with isotropic $(2.5 \times 2.5 \times$ $2.5 \mathrm{~mm}$ ) voxels, reconstructed to $1.875 \times 1.875 \times 2.5 \mathrm{~mm}$. Image acquisition was synchronised to the cardiac cycle using a peripheral gating device placed on the subject's forefinger. Echo time was $107 \mathrm{~ms}$ while the effective repetition time was $15 \mathrm{R}-\mathrm{R}$ intervals. Duration of the diffusion encoding gradients was $17.3 \mathrm{~ms}$ giving a maximum diffusion-weighting of $1,300 \mathrm{~s} \mathrm{~mm}^{-2}$. At each slice location, seven images were acquired with no diffusion gradients applied $(b=0)$, together with 64 diffusion-weighted images in which gradient directions were uniformly distributed in space.

Following correction of the diffusion-weighted images for image distortions introduced by the diffusion-weighting gradients, in-house software was used to 1) remove nonbrain tissue and 2) determine the diffusion tensor in each voxel (Basser et al. 1994a, b). Images of 1) mean $\mathrm{T}_{2}$ weighted intensity (with no diffusion gradients applied) and 2) FA were computed for each subject. Full details are given elsewhere (Jones et al. 2002a). FA which is an intravoxel measure of the degree to which there is a preferential direction of diffusion of water molecules within tissue has values ranging from $0-1$ (perfectly isotropic to perfectly anisotropic diffusion) and provides a measure of "tissue integrity" (Horsfield and Jones 2002; Jones et al. 2002b; Mori and Zhang 2006).

A 3D inversion recovery prepared spoiled gradient recalled acquisition in the steady state (IR-SPGR) scan [repetition time $(\mathrm{TR})=11.9 \mathrm{~ms}$, echo time $(\mathrm{TE})=5.2 \mathrm{~ms}$, inversion time $(\mathrm{TI})=450 \mathrm{~ms}$ ] was also acquired in the same scanning session. Images were acquired with a $256 \times 192$ matrix over a $200 \times 160 \mathrm{~mm}$ field of view, and reconstructed to a $256 \times 256$ matrix, giving a final in plane pixel size of $0.78125 \mathrm{~mm}$. Data were collected, in a coronal orientation, from $1241.5 \mathrm{~mm}$ thick sections.

\section{Pre-processing DT-MRI data}

Any scans demonstrating image corruption or motion artefacts were excluded. As mentioned earlier, a DT-MRI scan for one 22q11DS subject demonstrated excessive motion artefact and as a result, both structural and DTMRI scans for this individual were excluded from the imaging pipeline. To facilitate a voxel-based comparison of 
FA between subjects, images were preprocessed using SPM2 (Wellcome Department of Imaging Neuroscience, University College London) within MATLAB 6.5.2 (The MathWorks, Natick, MA, USA) and used a two stage approach. DT-MRI group mapping techniques (derived from Voxel-Based Morphometry (VBM) analysis methods developed for structural $\mathrm{T}_{1}$ and/or $\mathrm{T}_{2}$-weighted images) aligned DT-MRI data into standard space.

\section{Normalisation}

We performed a two stage normalisation. The first step was to align all the scans into standard Montreal Neurological Institute (MNI) space using the $\mathrm{T}_{2}$-weighted (non-diffusion-weighted) images of the DT-MRI data. We then used parameters from this registration to map all the FA images into MNI space, and average them to generate a customised FA template. Finally, we re-registered all the original FA images to this new FA template. Use of such a study specific, "half way", template reduces the bias that would otherwise exist due to the larger degree of warping needed to match the 22q11DS brains than the control brains to a standard (control subject based) template.

\section{Smoothing}

Scans need to be smoothed in order to reduce confounds due to individual variation in WM anatomy. Smoothing the data in order to coerce it into the appropriate statistical distribution is also a prerequisite for some analysis approaches, but is not necessary for our non-parametric approach (see below). The degree of smoothing to apply is still a subject of much discussion as different smoothing levels result in varying results (Jones et al. 2005); in the absence of a specific hypothesis about the spatial extent of any abnormalities, we applied a smoothing filter (Gaussian, $5 \mathrm{~mm}$ full-width at half maximum) to aid between-subject anatomical matching and improve the signal-to-noise ratio.

\section{Segmentation and masking}

The registered FA images were segmented to give maps of the probability of a tissue being either white or grey matter, and these segmented images were thresholded at a low level $(10 \%)$ to provide a binary mask of WM; visual inspection of example datasets confirmed that masking at this threshold produced maps which included all major WM areas, and did not suffer from any unexpected 'holes' (e.g. in low FA regions caused by crossing fibres). An accurate segmentation was not essential, and a relatively liberal threshold was used deliberately, in order to create a slightly 'over inclusive' mask.
Statistics

\section{Demographic, genetic and behavioural data}

Statistical analysis was performed in SPSS (SPSS 14.0 for Windows, SPSS Inc, Chicago, IL, USA). Student's t-test ( $p<$ 0.05 , two-tailed) for independent samples was used to examine between-group differences on age and IQ and ASQ, SDQ and schizotypy scores while the binomial test assessed COMT and gender distribution ( $p<0.05$, two-tailed).

\section{DT-MRI group mapping}

We examined the statistical significance of between group differences in FA using a non-parametric permutation-based method. Locally developed software, XBAM (version 3.4) (IoP, http://www.brainmap.co.uk/) measured between group differences at each intracerebral voxel in standard space by fitting an analysis of covariance model (ANCOVA) where FA was the dependent variable and group classification as the key predictor variable. In additional analyses, IQ and gender were also used as covariates in between-group comparisons.

Given that brain changes are likely to extend over a number of contiguous voxels, test statistics incorporating spatial information such as 3D cluster mass (the sum of suprathreshold voxel statistics), are generally more powerful than other possible test statistics, which are informed only by data at a single voxel (Bullmore et al. 1999). The voxelwise statistic images were therefore thresholded at a relatively lenient level of $p<0.05$, and voxels that were spatially contiguous in three dimensions in the thresholded maps were assigned to the same cluster. The sum of voxel statistics within each cluster was computed for each randomisation to form a distribution of cluster mass under the null hypothesis.

As no parametric distribution is known for cluster mass, permutation testing was used to assess statistical significance; the mass of each cluster in the observed data was compared to this randomised distribution, and significant clusters were defined as those that had a greater cluster mass than the randomised distribution at a particular significance level. Such a non-parametric approach also overcomes the assumption that parametric methods adopt that the residuals of the model tested will follow a Gaussian distribution (which has been shown to not always be true for DT-MRI data, even after extensive smoothing) (Jones et al. 2005).

At this stage, we considered only those voxels at which all subjects contribute data which, along with the masking procedure above, restricted the analysis to core WM regions. This reduced the search volume (and thus the number of comparisons made) and also avoided testing at the grey/white interfaces, where the high grey/white contrast of FA images exacerbates any edge effects. 
Overall, analyses are reported at a stringent adaptive cluster level threshold where the expected number of false-positive clusters is less than one per analysis. XBAM reported coordinates of the centre of mass of clusters in MNI space which is used by SPM; MNI coordinates were subsequently converted to Talairach space via a non-linear transformation (Brett et al. 2002) (details at http://imaging.mrc-cbu.cam.ac. uk/imaging/MniTalairach) and these were interpreted with the aid of known neuroanatomical pathways (Talairach and Tournoux 1988; Mori et al. 2005).

\section{Voxel-based morphometry (VBM)}

The pre-processing and processing steps of our structural MRI data have been published previously (Ashburner and Friston 2000). In brief, we used SPM5 (Wellcome Department of Imaging Neuroscience, University College London, UK) which integrates initial tissue classification and registration into a single model and also includes correction of the effects of image intensity non-uniformity often termed the 'bias field'(Ashburner and Friston 2005). WM was extracted from the normalised images and "modulated" to compensate for the effects of spatial normalisation. Modulation consists of multiplying each voxel value by its relative volume before and after warping, in order to compensate for the fact that spatial normalisation expands/contracts some brain regions. After modulation, the total amount of white (or grey) matter is the same as in the original images. Good and colleagues (Good et al. 2001) note that "in effect, an analysis of modulated data tests for regional differences in the absolute amount (volume) of grey matter." Images were then smoothed by convolution with a $5 \mathrm{~mm}$ Gaussian kernel. The maps so produced are referred to as images of "grey (or white) matter volume" to distinguish them from the images of "concentration" or "density" which result if the modulation stage is omitted. Additionally, global WM volumes were extracted via SPM5 and between group differences were compared using Student's t-tests. If global volumes significantly differ, these are then entered as further covariates in between-group analyses.

As with DT-MRI, structural brain changes are likely to extend over a number of contiguous voxels and thus permutation testing was also used to assess statistical significance, in this case using the XBAMM programme; details of which can be found at http://www-bmu.psychi atry.cam.ac.uk/software/docs/xbamm/. IQ was also used as a covariate in additional between-group analysis.

\section{Post hoc analysis of Schizotypy scores}

We carried out a preliminary (post hoc) analysis to determine if significant differences in WM FA were associated with behavioural variation within people with 22q11DS. To do this, we extracted mean FA values from each of the clusters that were significantly different from healthy controls. We then related these values (using Pearson product-moment correlation coefficients) to severity of schizotypy (Campbell et al. 2006). A Bonferroni adjusted alpha of 0.025 was subsequently applied.

\section{Post hoc analysis of COMT status}

Finally, we carried out a second preliminary investigation within people with 22q11DS by comparing the WM FA and volume of those with ${ }^{\mathrm{V}}$ COMT to their counterparts with ${ }^{\mathrm{M}} \mathrm{COMT}$.

\section{Results}

Demographic, genetic and behavioural data

The groups did not differ significantly in age, or gender distribution. However, as expected, the mean FSIQ of those with 22q11DS was significantly lower; also mean SDQ, ASQ and schizotypy scores were higher in VCFS individuals than controls. Six 22q11DS subjects and one healthy subject scored above the cut-off of 7 in the ASQ. With regard to COMT status, seven subjects with 22q11DS had ${ }^{\mathrm{V}} \mathrm{COMT}$ while four had ${ }^{\mathrm{M}}$ COMT (Table 1).

\section{Group contrasts of FA using DT-MRI group mapping}

\section{$22 q 11 D S$ vs. controls FA (not controlled for IQ)}

Relative to controls, WM FA in 22q11DS subjects was significantly reduced in the frontal, parietal and temporal lobes of the left hemisphere. The centre of the most significant cluster was localised to the WM of the superior thalamic radiation and the cluster encompassed the: 1) projections from the thalamus to the parietal lobe via the posterior limb of the internal capsule; 2) projections from the motor cortex of the frontal lobe to the posterior limb of the internal capsule via the superior region of the corona radiata; 3) tapetum (Dejerine 1895; Crosby et al. 1962) lateral to the posterior horn of the lateral ventricle; 4) posterior thalamic radiation; and 5) the fronto-parietal course of the arcuate fasciculus (AF) (Fig. 1, Table 2).

In contrast, people with 22q11DS had a significantly increased FA relative to controls (again, exclusively in the left hemisphere) in regions that were anatomically more anterior and inferior to the FA decreases described above. The most significant clusters of FA increases included the $\mathrm{WM}$ of the genu/anterior limb of the internal capsule together with the anterior and superior portions of the corona radiata. 


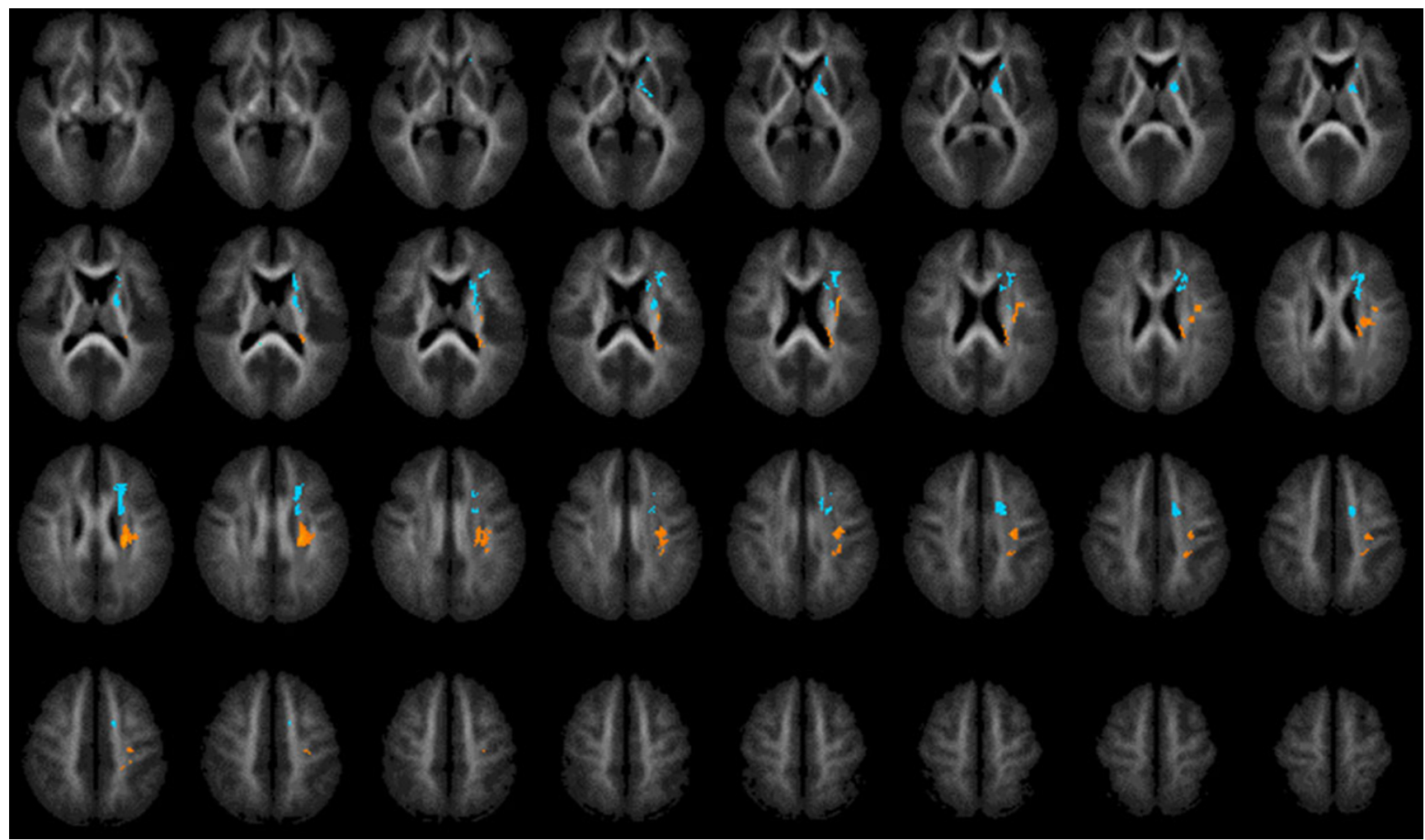

Fig. 1 Fractional anisotropy (FA) in 22q11DS subject group vs. control group (not controlled for IQ). Higher FA in controls than in 22q11DS subjects (orange). Higher FA in 22q11DS subjects than in controls (blue). Ascending $2 \mathrm{~mm}$ transverse sections; (reversed where L= R, R $=\mathrm{L}$ )

Table 2 Cluster localisation for significant differences in white matter fractional anisotropy (FA)

DT-MRI group mapping of white matter FA of 22q11DS subjects vs. controls (cluster significance threshold $p=0.0005$ )

\section{Not controlled for IQ}

White matter FA deficits in 22q11DS subjects

\begin{tabular}{|c|c|c|c|c|}
\hline \multirow[t]{2}{*}{$\begin{array}{l}\text { Cluster size } \\
\text { (number of voxels) }\end{array}$} & \multicolumn{2}{|c|}{$\begin{array}{c}\text { Talairach and } \\
\text { Tournoux } \\
\text { coordinates }\end{array}$} & \multirow[t]{2}{*}{ Region/tract } & \multirow[t]{2}{*}{ Hemisphere } \\
\hline & & $\mathrm{y} \quad \mathrm{z}$ & & \\
\hline 378 & -23 & $-22 \quad 23$ & $\begin{array}{l}\text { Internal capsule (posterior limb)/superior region of the corona radiata/tapetum/posterior } \\
\text { thalamic radiation/arcuate fasciculus }\end{array}$ & Left \\
\hline \multicolumn{5}{|c|}{ White matter FA excesses in 22q11DS subjects } \\
\hline 463 & -13 & $5 \quad 0$ & $\begin{array}{l}\text { Genu and anterior limb of internal capsule/anterior and superior portions of the corona } \\
\text { radiata }\end{array}$ & Left \\
\hline \multicolumn{5}{|c|}{${ }^{\prime}$} \\
\hline \multicolumn{5}{|c|}{ White matter FA deficits in 22q11DS subjects } \\
\hline 201 & -13 & $-15-11$ & Brainstem including corticopontine and corticospinal tracts and middle cerebellar peduncle & Left \\
\hline 280 & 30 & $-25-4$ & $\begin{array}{l}\text { Internal capsule (retrolenticular and posterior limbs)/inferior fronto-occipital fasciculus/ } \\
\text { inferior longitudinal fasciculus/hippocampus }\end{array}$ & Right \\
\hline 180 & -21 & -205 & Posterior limb of internal capsule/hippocampus & Left \\
\hline 699 & -9 & -3711 & Splenium of corpus callosum/superior corona radiata & Left \\
\hline 752 & 14 & -3913 & Splenium of corpus callosum/superior corona radiata & Right \\
\hline 150 & 9 & $-2 \quad 22$ & Body of corpus callosum/cingulum & Right \\
\hline
\end{tabular}


When gender was added as a covariate, a small cluster was localised to the left frontal lobe but subsequently did not reach statistical significance when correction for type I error was applied.

\section{2q11DS vs. controls FA (controlled for IQ)}

Significant widespread FA deficits were found in the 22q11DS group relative to healthy controls that extended from the brainstem to more superior brain sections. These deficits were mainly bilateral and found in structures close to the mid-line such as the corpus callosum, internal capsule and cingulum but also more laterally in temporal and parietal lobe regions. There were no regions of increased FA in the 22q11DS group relative to controls (Fig. 2, Table 2).

FA deficits in the brainstem encompassed the right corticopontine, corticospinal and middle cerebellar peduncle while the corpus callosum was found to have reduced FA especially in the splenium, tapetum and body and to a lesser extent in the genu. FA deficits were found in the cingulum adjacent to the body of the corpus callosum and in the uncinate fasciculus in the temporal lobe. The hippocampi and inferior longitudinal and inferior frontooccipital fasciculi in the temporal lobes were found to have reduced FA bilaterally while the bilateral corona radiata in the occipital and parietal lobes showed FA deficits.

Within 22q11DS, a preliminary analysis of Schizotypy and differences in $F A$

There was a significant negative correlation between high schizotypy scores and decreased WM FA in the right posterior limb of internal capsule $(r=-0.822, p=0.023)$, right body of corpus callosum $(r=-0.827, p=0.022)$ and left splenium of corpus callosum $(r=-0.851, p=0.015)$.

Within 22q11DS, a preliminary analysis of COMT variation

22q11DS individuals with ${ }^{\mathrm{V}}$ COMT had significantly lower FA than their counterparts with ${ }^{\mathrm{M}} \mathrm{COMT}$. The most signi-

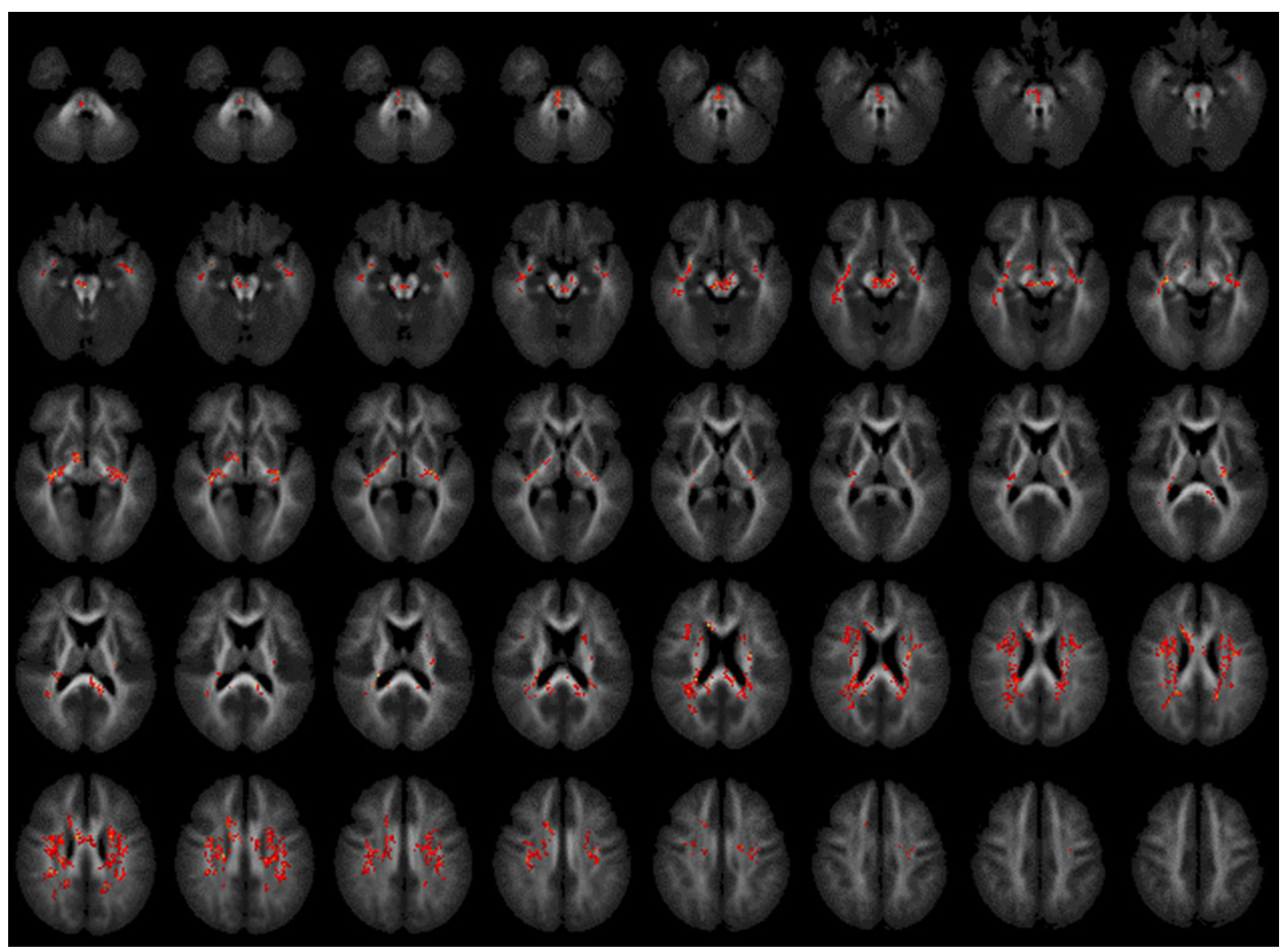

Fig. 2 FA in 22q11DS subject group vs. control group (controlled for IQ). Significant FA deficits in 22q11DS (red). Ascending 2 mm transverse sections; (reversed where $\mathrm{L}=\mathrm{R}, \mathrm{R}=\mathrm{L}$ ) 
ficant differences were found bilaterally in the: 1) anterior cingulum; 2) frontal lobe; and 3) corpus callosum. However, 22q11DS people with ${ }^{\mathrm{V}} \mathrm{COMT}$ also had a unilateral FA reduction in right hemisphere regions incorporating the: 1) forceps minor; 2) inferior fronto-occipital and uncinate fasciculi; and 3) anterior/superior corona radiata (Fig. 3, Table 3).

Group contrasts of WM volume using VBM

$22 q 11 D S$ vs. controls WM volume (not controlled for IQ)

Mean global WM volume did not differ significantly between young people with 22q11DS and controls (mean= $385 \mathrm{ml}, \mathrm{SD} \pm 36.5 \mathrm{ml}$ vs. mean $=418 \mathrm{ml}, \mathrm{SD} \pm 62.2 \mathrm{ml}$ respectively; $p=0.138$ ) (refer to Table 1 for details of global volumes). However, there were significant differences in the regional distribution of WM (Fig. 4, Table 4).

Young people with 22q11DS, compared to controls, had a significant reduction bilaterally in the 1) middle cerebellar peduncle of the cerebellum and brainstem; 2) optic radiation and lingual, middle and inferior occipital gyri; 3 ) cuneus and precuneus; 4) posterior thalamic radiation; 5) body, genu and tapetum of the corpus callosum; 6) hippocampus; and 7) paracentral lobule. In contrast, 22q11DS people had a significantly greater WM volume bilaterally in the 1) anterior limb and genu of the internal capsule; 2) WM tracts from the basal ganglia; 3) medial frontal gyrus and cingulum; and 4) body and splenium of the corpus callosum.

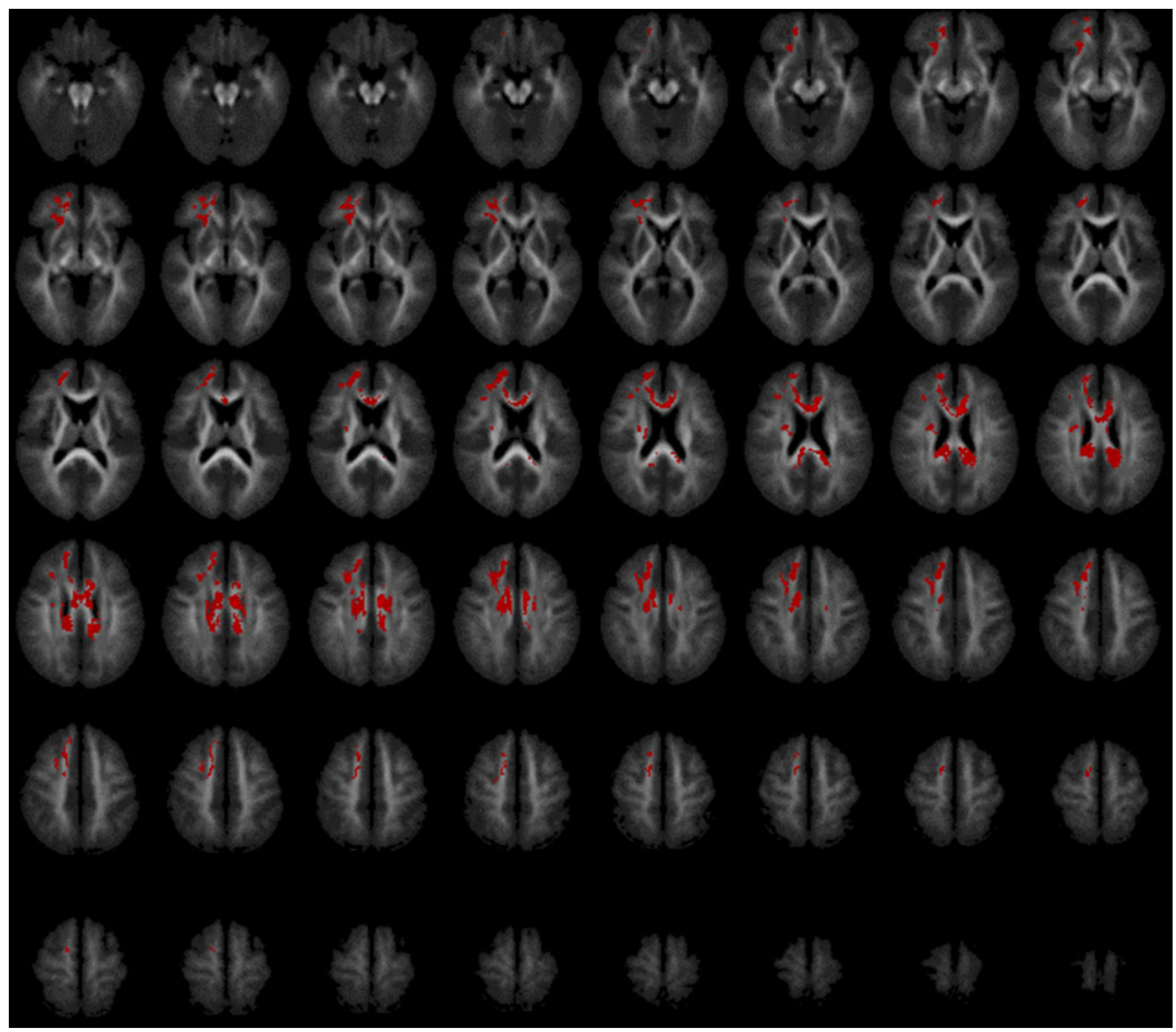

Fig. 3 Fractional anisotropy deficits within 22q11DS group in subjects with ${ }^{\mathrm{V}}$ COMT relative to ${ }^{\mathrm{M}} \mathrm{COMT}$. Ascending 2 mm transverse sections; (reversed where $\mathrm{L}=\mathrm{R}, \mathrm{R}=\mathrm{L}$ ) 
Table 3 Genetic influence of COMT allele variation on white matter fractional anisotropy (FA) and volume

\begin{tabular}{|c|c|c|c|c|}
\hline \multicolumn{5}{|c|}{$\begin{array}{l}\text { White matter FA reduction of 22q11DS subjects with }{ }^{\mathrm{V}} \text { COMT vs. }{ }^{\mathrm{M}} \mathrm{COMT} \text { (cluster significance threshold } p=0.00175 \text { ) } \\
{ }^{M} \text { COMT }>{ }^{V} \text { COMT FA }\end{array}$} \\
\hline \multirow[t]{2}{*}{$\begin{array}{l}\text { Cluster size (number of } \\
\text { voxels) }\end{array}$} & \multicolumn{2}{|c|}{$\begin{array}{c}\text { Talairach and } \\
\text { Tournoux } \\
\text { coordinates }\end{array}$} & \multirow[t]{2}{*}{ Region/tract } & \multirow[t]{2}{*}{ Hemisphere } \\
\hline & $\mathrm{x}$ & $\mathrm{y} \quad \mathrm{z}$ & & \\
\hline \multirow[t]{2}{*}{2721} & -7 & -6 & Anterior cingulum/frontal lobe/corpus callosum & Bilateral \\
\hline & & & $\begin{array}{l}\text { Forceps minor/inferior fronto-occipital and uncinate fasciculi/anterior and superior } \\
\text { corona radiata }\end{array}$ & Right \\
\hline \multicolumn{5}{|c|}{$\begin{array}{l}\text { White matter volume reduction of } 22 q 11 D S \text { subjects with }{ }^{\mathrm{V}} \text { COMT vs. }{ }^{\mathrm{M}} \mathrm{COMT} \text { (cluster significance threshold } p=0.005 \text { ) } \\
{ }^{M} \text { COMT }>{ }^{V} \text { COMT Volume }\end{array}$} \\
\hline \multirow[t]{2}{*}{$\begin{array}{l}\text { Cluster size (number of } \\
\text { voxels) }\end{array}$} & \multicolumn{2}{|c|}{$\begin{array}{l}\text { Talairach and } \\
\text { Tournoux } \\
\text { Coordinates }\end{array}$} & Region & Hemisphere \\
\hline & & $\mathrm{y} \quad \mathrm{z}$ & & \\
\hline 212 & -36 & $-35-2$ & Hippocampus and superior/middle/inferior temporal gyri & Left \\
\hline 374 & 7 & 20 & Anterior limb of internal capsule & Right \\
\hline 329 & 25 & -2 & Retrolenticular limb of internal capsule & Right \\
\hline 4924 & 8 & $-14 \quad 28$ & Cingulum and corpus callosum & Bilateral \\
\hline 213 & 30 & $-36 \quad 31$ & Supramarginal gyrus & Right \\
\hline
\end{tabular}

\section{$22 q 11 D S$ vs. controls WM volume (controlled for IQ)}

WM volume was found to be significantly increased relative to healthy controls. These regional increases were mainly bilateral and found in the brainstem, the internal capsule (posterior limb and genu) and superior corona radiata while unilateral increases were found in the posterior corona radiata in the right occipital lobe and in the left pre-central gyrus. There were no regions of WM volume reduction in 22q11DS (Fig. 5, Table 4).

\section{Within 22q11DS, a preliminary analysis on the effect of COMT genotype}

${ }^{\mathrm{v}}$ COMT 22q11DS individuals had a significantly decreased WM volume relative to those with ${ }^{\mathrm{M}} \mathrm{COMT}$ bilaterally in the 1) frontal lobes; 2) cingulum; 3) corpus callosum; 4) internal capsule; 5) hippocampus; and 6) superior and middle temporal gyri; and unilaterally in the right inferior temporal and supramarginal gyri (Fig. 6, Table 3).

\section{Discussion}

In this cross sectional study we compared measures of WM microstructural integrity and volume using DT-MRI group mapping and VBM respectively in young people with 22q11DS and healthy controls. Also, within 22q11DS, we carried out a preliminary analysis of the relationship between WM abnormalities and schizotypy, and with variation in COMT genotype.

In young people with 22q11DS, we found reduced FA in numerous brain regions as compared to controls. However, and consistent with previous DT-MRI studies (BarneaGoraly et al. 2003; Simon et al. 2005), these predominantly affected the parietal lobe. When IQ was included as a covariant in the analysis, FA deficits in the corpus callosum, internal capsule, AF and thalamic radiations remained significant. It has been suggested that a reduction in FA is caused by damage to highly-aligned axonal structures or replacement of axonal fibres with less tightly organised cells (Horsfield and Jones 2002). Therefore these differences in FA may be associated with impaired 'connectivity' in a number of neural systems, and confirm earlier reports of widespread deficits in microstructural integrity in 22q11DS.

We also found higher FA in 22q11DS relative to controls that were localised to regions distinct from the FA reductions described above. These occurred exclusively in the left hemisphere and particularly in the left internal capsule. Higher FA has previously been reported (BarneaGoraly et al. 2003; Simon et al. 2005) but it has been suggested that higher FA reported by others in 22q11DS may be artefactual - because 22q11DS brains are abnormally shaped and so may not register perfectly to the brain template that is typically used in imaging studies (e.g. healthy child or adult templates) during the normalisation step in SPM. As noted in our methods, we addressed this 


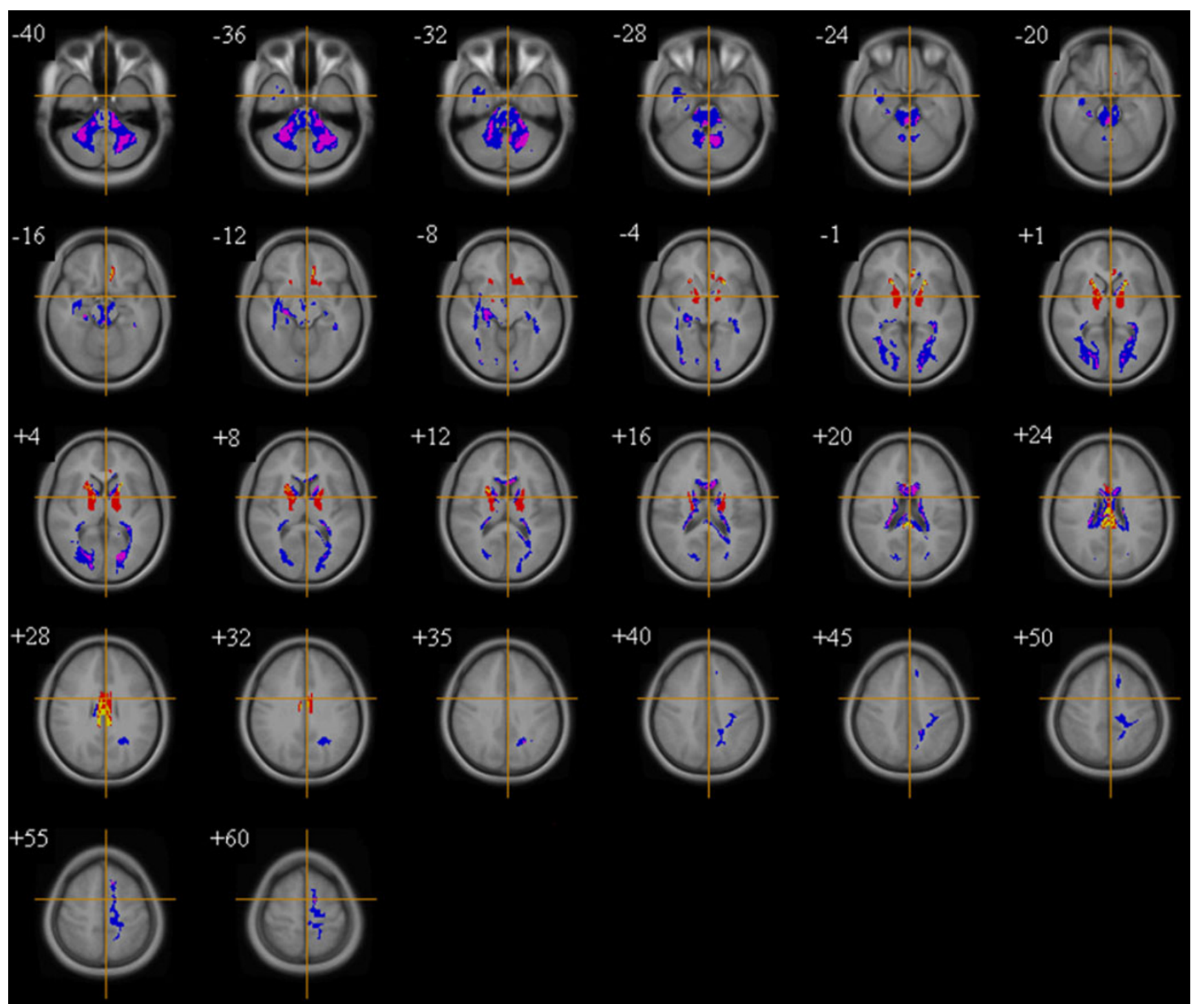

Fig. 4 White matter volume in 22q11DS subjects vs. controls (not controlled for IQ). Volumetric excesses in 22q11DS (red/yellow). Volumetric deficits in 22q11DS (blue/purple). Ascending transverse sections; (reversed where $\mathrm{L}=\mathrm{R}, \mathrm{R}=\mathrm{L}$ )

potential confound by employing a customised FA brain template derived from all the subjects under study, aiming to minimise both the degree of warping needed for any individual subject, and bias in such warping between the groups. Increased FA did not remain significant in 22q11DS when we included IQ as a covariate, although this may simply reflect a loss of sensitivity (i.e. a type II error) due to the inclusion of two strongly correlated variables (IQ and group) in the analysis (Miller and Chapman 2001). Compared to previous DTI reports in 22q11DS, our study is the first to covary for IQ, and this combined with template considerations (i.e. our use of a study specific template), may have resulted in our findings differing from other work.

In our VBM analyses of WM proportion, regional increases and decreases of volume were found within young people with 22q11DS. A bilateral reduction in WM was found (consistent with prior reports (Eliez et al. 2000; Kates et al. 2001; van Amelsvoort et al. 2001, 2004; Campbell et al. 2006)) in regions such as the cerebellum, corpus callosum, and occipital and medial temporal lobes. Although, these findings did not remain significant when covaried for IQ, increased WM proportion bilaterally in regions close to the mid-line cerebral structures did; and particularly in the posterior limb of the internal capsule and superior corona radiata. Unilateral increases were also found in the right posterior corona radiata and left pre-central gyrus. Our finding of increased WM volume in the frontal lobe contrasts with a previous study which concurrently examined WM FA and volume in 22q11DS (Simon et al. 2005) that reported right middle frontal gyrus volume reduction but supports the finding of relatively increased frontal WM 
Table 4 Cluster localisation for significant differences in white matter volume

VBM analysis of white matter volume of 22 q11DS subjects vs. controls (cluster significance threshold $p=0.006$ )

\section{Not controlled for IQ}

White matter volume deficits in 22q11DS subjects

\begin{tabular}{|c|c|c|c|c|c|}
\hline \multirow[t]{2}{*}{$\begin{array}{l}\text { Cluster size (number of } \\
\text { voxels) }\end{array}$} & \multicolumn{3}{|c|}{$\begin{array}{l}\text { Talairach and } \\
\text { Tournoux } \\
\text { Coordinates }\end{array}$} & \multirow[t]{2}{*}{ Region } & \multirow[t]{2}{*}{ Hemisphere } \\
\hline & $\mathrm{x}$ & $\mathrm{y}$ & $\mathrm{z}$ & & \\
\hline 4218 & 1 & -36 & -11 & Brainstem/cerebellum & Right \\
\hline 149 & 34 & -19 & -9 & Hippocampus & Right \\
\hline 77 & -33 & -35 & -2 & Hippocampus & Left \\
\hline 533 & 28 & -71 & 6 & $\begin{array}{l}\text { Middle occipital gyrus/optic radiation and lingual, middle and inferior occipital gyri/ } \\
\text { cuneus and precuneus }\end{array}$ & Right \\
\hline 688 & 8 & -11 & 23 & Body, genu and splenium of corpus callosum & $\begin{array}{l}\text { Inter- } \\
\text { hemispheric }\end{array}$ \\
\hline 489 & -12 & -17 & 52 & Medial frontal gyrus/paracentral lobule & Left \\
\hline \multicolumn{6}{|c|}{ White matter volume excesses in $22 q 11 D S$ subjects } \\
\hline 133 & -8 & 28 & -15 & Corpus callosum/cingulum/medial frontal gyrus & Left \\
\hline 459 & -13 & 5 & 1 & Globus pallidus/anterior limb and genu of internal capsule & Left \\
\hline 396 & 20 & 1 & 3 & Putamen/anterior limb and genu of internal capsule & Right \\
\hline 341 & 2 & -13 & 25 & Corpus callosum/cingulum & $\begin{array}{l}\text { Inter- } \\
\text { hemispheric }\end{array}$ \\
\hline \multicolumn{6}{|l|}{ Controlled for IQ } \\
\hline \multicolumn{6}{|c|}{ White matter volume excesses in $22 q 11 D S$ subjects } \\
\hline 108 & 3 & -19 & -23 & Brainstem & Right \\
\hline 602 & -17 & -12 & 7 & Posterior limb and genu of internal capsule and superior corona radiata & Left \\
\hline 771 & 23 & -13 & 8 & Posterior limb and genu of internal capsule & Right \\
\hline 210 & 22 & -75 & 19 & Posterior corona radiata, occipital lobe and superior corona radiata & Right \\
\hline 85 & -36 & -2 & 30 & Pre-central gyrus & Left \\
\hline
\end{tabular}

volume in other studies of 22q11DS (Eliez et al. 2000; Antshel et al. 2008).

Overall, a number of findings for FA and volume were not co-located after IQ was covaried for e.g. reduced FA in the corpus callosum where reduction in WM volume was absent. Therefore in such regions, the differences in FA cannot be accounted for simply by differences in WM volume (and vice versa). However, there were also regions where reduced FA but increased volume both occurred for instance, in the frontal lobes. It is possible that given 22q11DS is associated with cortical dysgenesis, an increased number of ectopic neurones in the WM may account for a reduced FA in association with a relatively increased volume that may be attributed to a loss of directional organisation with a relative preservation or increase of cell density (Wieshmann et al. 1999; Trivedi et al. 2006). Therefore, (wherever possible) both sMRI and DT-MRI should be used together to investigate WM pathology given that the latter may be able to detect abnormalities in normal appearing WM on conventional MRI (Rugg-Gunn et al. 2001; Makki et al. 2007).
As some of the differences we found in WM microstructural integrity may affect behaviour and/or risk for developing psychosis, we investigated for the first time, the relationship between schizotypy and WM FA in brain regions which differed significantly between young people with 22q11DS and controls. We found a significant negative correlation between increased schizotypy scores and reduced FA in the clusters that encompassed WM of the right posterior limb of internal capsule and the right body and left splenium of corpus callosum within young people with 22 q11DS. This may be relevant to the nondeleted general population as the internal capsule contains reciprocal WM fibres from the thalamus to the cerebral cortex and reduced FA of the corpus callosum and internal capsule has been previously reported in schizophrenia (Buchsbaum et al. 2006; Mitelman et al. 2007). Our pilot evidence provides tentative support for the suggestion that microstructural abnormalities in these WM tracts may partially explain some schizotypic behaviours in 22q11DS but these results however require replication in future studies. 


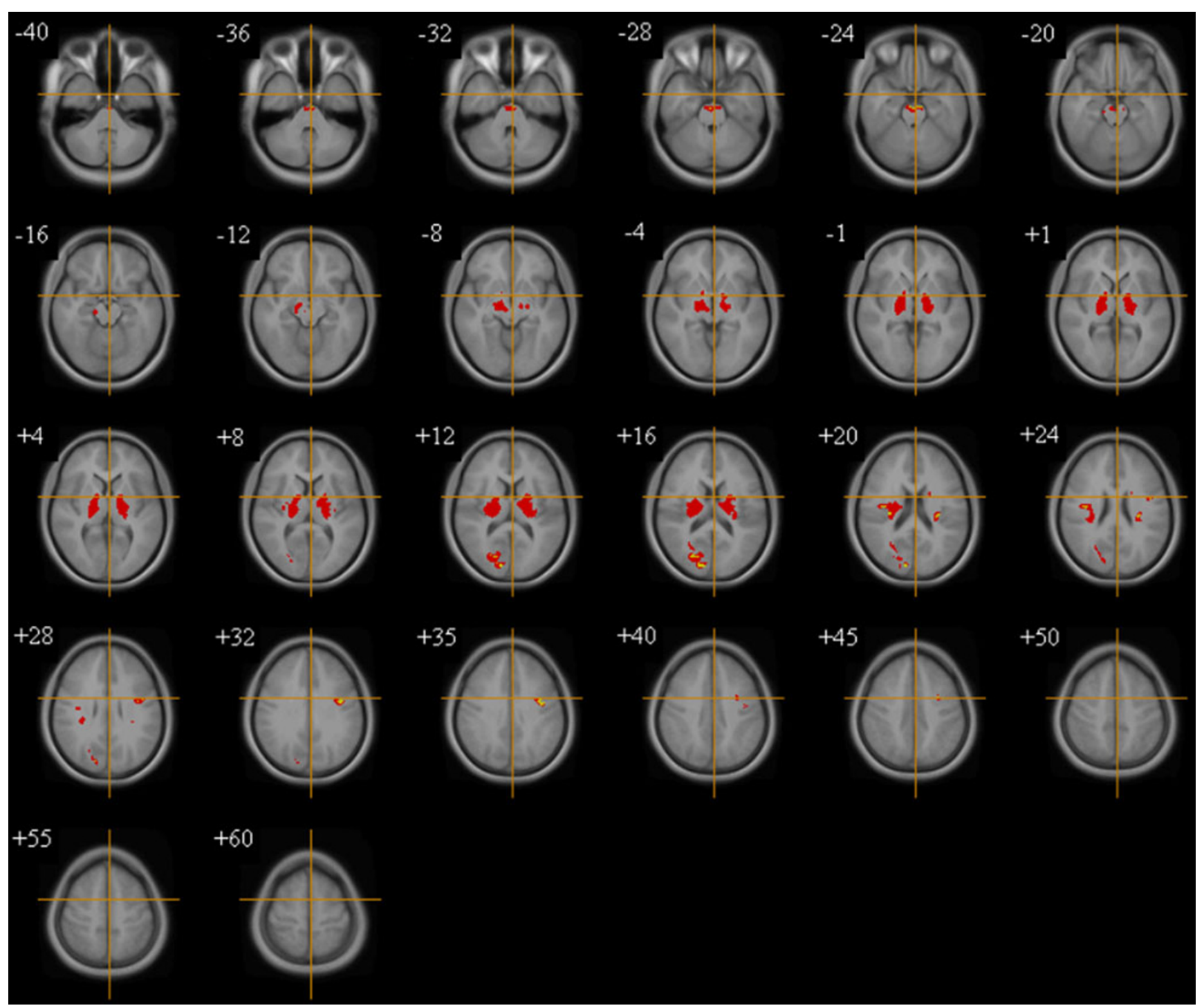

Fig. 5 White Matter volume in 22q11DS subjects vs. controls (controlled for IQ). Significant volumetric excesses in 22q11DS (red/yellow). Ascending transverse sections; (reversed where $\mathrm{L}=\mathrm{R}, \mathrm{R}=\mathrm{L}$ )

We conducted a further preliminary investigation on the effect of COMT polymorphism within 22q11DS youngsters where ${ }^{\mathrm{V}}$ COMT was found to be associated with significant reduction in local WM volume; and perhaps especially in the frontal lobes, cingulum and corpus callosum. Similarly, we also found preliminary evidence for decreased FA in these same regions. As COMT activity is largely responsible for dopamine modulation in the pre-frontal cortex (PFC) (Tunbridge et al. 2004), haploinsufficiency of the COMT gene means that individuals with 22q11DS are exposed to high levels of prefrontal dopamine (Gothelf et al. 2008). COMT polymorphism is known to affect global brain development in both healthy adults (Zinkstok et al. 2006) and adults with 22q11DS (van Amelsvoort et al. 2008) where in the latter whole-brain investigation of 22q11DS adults by our group, we reported that variation in COMT activity not only affects the anatomy of the frontal lobes but also a number of nonfrontal regions. Most studies so far in children and adolescents have only assessed the PFC (Gothelf et al. 2005; Kates et al. 2006) and the results from our current study involving children and adolescents with 22q11DS demonstrate the widespread effects of COMT polymorphism that affects both the volume and microstructural integrity of WM which extends beyond frontal lobe anatomy.

Our study has a number of methodological considerations including, the sample size, cross-sectional design, lack of an FSIQ-matched control group, and the multiple comparisons we carried out (and therefore the increased risk for Type 1 error). However, we deliberately did not include a learning disabled control group as our study was 


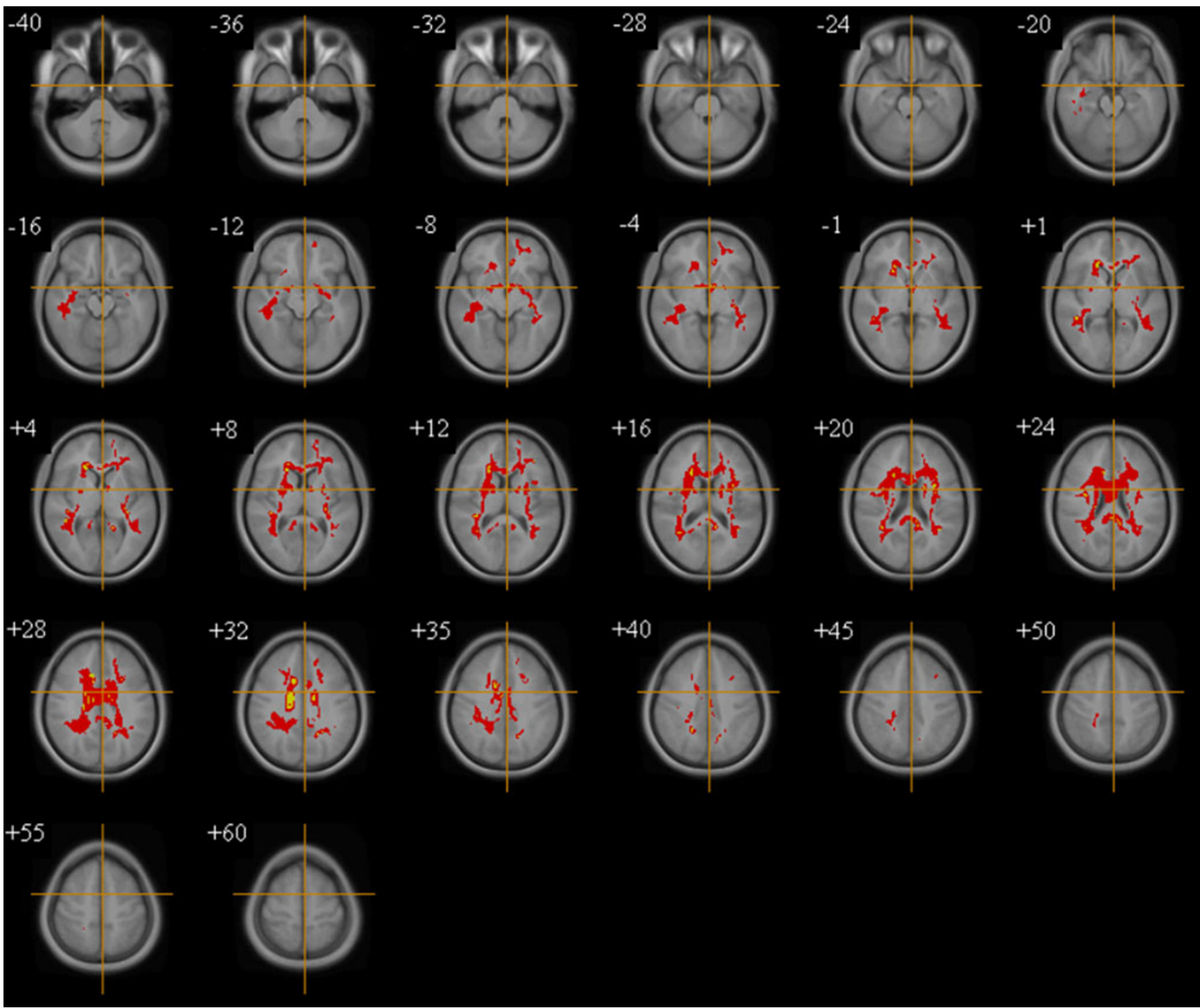

Fig. 6 White matter volume deficits within 22q11DS group in subjects with ${ }^{\mathrm{V}}$ COMT relative to ${ }^{\mathrm{M}} \mathrm{COMT}$. Ascending 2 mm transverse sections; (reversed where $\mathrm{L}=\mathrm{R}, \mathrm{R}=\mathrm{L}$ )

designed to address the question how people with 22q11DS differ from those with healthy brain development. It would be virtually impossible to recruit a 'perfect' control group of non-22q11DS controls with the same degree of learning disability as the 22q11DS probands. With regard to genetics, we only investigated COMT (because it modulates both brain maturation and psychosis) although a number of other important genes that impact on brain development are also deleted in the $22 \mathrm{q} 11.2$ region e.g. TBX-1 and PRODH. Our study does however have some strengths, for instance a customised FA brain template was used in order to reduce registration errors, and the level of significance was adapted in order to yield less than one false-positive cluster over the entire imaging volume investigated. Therefore, we feel Type 1 errors are unlikely to fully explain our results.
In conclusion, our study demonstrates that people with 22q11DS have widespread differences in both the microstructral integrity and volume of WM that are largely independent. Although WM volume may appear relatively normal as measured using standard MRI techniques, this does not necessarily indicate that the underlying WM microstructural integrity is also unaffected. Further studies on the relationship of WM differences to the behavioural phenotype of 22q11DS and to genetic variation are required.

Acknowledgements We thank all our patients and the control subjects for participating in this study.

We are grateful to the radiographers at the Centre for Neuroimaging Sciences for their help at scanning sessions.

Conflict of interest None 


\section{References}

Akil M, Kolachana BS, Rothmond DA, Hyde TM, Weinberger DR, Kleinman JE. Catechol-O-methyltransferase genotype and dopamine regulation in the human brain. J Neurosci. 2003;23 (6):2008-13.

Antshel KM, Peebles J, AbdulSabur N, Higgins AM, Roizen N, Shprintzen R, et al. Associations between performance on the Rey-Osterrieth Complex Figure and regional brain volumes in children with and without velocardiofacial syndrome. Dev Neuropsychol. 2008;33(5):601-22.

Ashburner J, Friston KJ. Voxel-based morphometry-the methods. Neuroimage. 2000;11(6 Pt 1):805-21.

Ashburner J, Friston KJ. Unified segmentation. Neuroimage. 2005;26 (3):839-51.

Baker KD, Skuse DH. Adolescents and young adults with 22q11 deletion syndrome: psychopathology in an at-risk group. $\mathrm{Br} \mathrm{J}$ Psychiatry. 2005; 186:115-20.

Barnea-Goraly N, Menon V, Krasnow B, Ko A, Reiss A, Eliez S. Investigation of white matter structure in velocardiofacial syndrome: a diffusion tensor imaging study. Am J Psychiatry. 2003; 160(10):1863-9.

Basser PJ, Mattiello J, LeBihan D. Estimation of the effective selfdiffusion tensor from the NMR spin echo. J Magn Reson B. 1994a; 103(3):247-54.

Basser PJ, Mattiello J, LeBihan D. MR diffusion tensor spectroscopy and imaging. Biophys J. 1994b;66(1):259-67.

Berument SK, Rutter M, Lord C, Pickles A, Bailey A. Autism screening questionnaire: diagnostic validity. $\mathrm{Br} \mathrm{J}$ Psychiatry. 1999;175:444-51.

Bongarzone ER, Howard SG, Schonmann V, Campagnoni AT. Identification of the dopamine D3 receptor in oligodendrocyte precursors: potential role in regulating differentiation and myelin formation. J Neurosci. 1998;18(14):5344-53.

Boot E, Booij J, Zinkstok J, Abeling N, de Haan L, Baas F, et al. Disrupted dopaminergic neurotransmission in 22q11 deletion syndrome. Neuropsychopharmacology. 2008;33(6):1252-8.

Brett M, Johnsrude IS, Owen AM. The problem of functional localization in the human brain. Nat Rev Neurosci. 2002;3(3):243-9.

Buchsbaum MS, Schoenknecht P, Torosjan Y, Newmark R, Chu KW, Mitelman S, et al. Diffusion tensor imaging of frontal lobe white matter tracts in schizophrenia. Ann Gen Psychiatry. 2006;5:19.

Bullmore ET, Suckling J, Overmeyer S, Rabe-Hesketh S, Taylor E, Brammer MJ. Global, voxel, and cluster tests, by theory and permutation, for a difference between two groups of structural MR images of the brain. IEEE Trans Med Imaging. 1999;18 (1):32-42.

Campbell LE, Daly E, Toal F, Stevens A, Azuma R, Catani M, et al. Brain and behaviour in children with 22q11.2 deletion syndrome: a volumetric and voxel-based morphometry MRI study. Brain. 2006;129(Pt 5):1218-28.

Chapman LJ, Chapman JP, Kwapil TR, Eckblad M, Zinser MC. Putatively psychosis-prone subjects 10 years later. J Abnorm Psychol. 1994;103(2):171-83.

Chen J, Lipska BK, Halim N, Ma QD, Matsumoto M, Melhem S, et al. Functional analysis of genetic variation in catechol-Omethyltransferase (COMT): effects on mRNA, protein, and enzyme activity in postmortem human brain. Am J Hum Genet. 2004;75(5):807-21.

Cheverud JM. Quantitative genetics and developmental constraints on evolution by selection. J Theor Biol. 1984;110(2):155-71.

Crosby EC, Humphrey T, Lauer EW. Correlative anatomy of the nervous system. New York: Macmillian Co.; 1962.

Dejerine J. Anatomie des Centres Nerveux, vol. 1. Paris: Rueff et Cie; 1895.
Eliez S, Schmitt JE, White CD, Reiss AL. Children and adolescents with velocardiofacial syndrome: a volumetric MRI study. Am J Psychiatry. 2000;157(3):409-15.

Feinstein C, Eliez S. The velocardiofacial syndrome in psychiatry. Curr Opin Psychiatry. 2000;13:485-90.

Good CD, Johnsrude IS, Ashburner J, Henson RN, Friston KJ, Frackowiak RS. A voxel-based morphometric study of ageing in 465 normal adult human brains. Neuroimage. 2001;14(1 Pt 1):21-36.

Goodman FR. Congenital abnormalities of body patterning: embryology revisited. The Lancet. 2003;362(9384):651-62.

Goodman R, Ford T, Simmons H, Gatward R, Meltzer H. Using the strengths and difficulties questionnaire (SDQ) to screen for child psychiatric disorders in a community sample. Br J Psychiatry. 2000;177:534-9.

Gothelf D, Lombroso PJ. Genetics of childhood disorders: XXV. Velocardiofacial syndrome. J Am Acad Child Adolesc Psychiatry. 2001;40(4):489-91.

Gothelf D, Eliez S, Thompson T, Hinard C, Penniman L, Feinstein C, et al. COMT genotype predicts longitudinal cognitive decline and psychosis in 22q11.2 deletion syndrome. Nat Neurosci. 2005;8 (11):1500-2.

Gothelf D, Schaer M, Eliez S. Genes, brain development and psychiatric phenotypes in velo-cardio-facial syndrome. Dev Disabil Res Rev. 2008;14(1):59-68.

Hoglinger GU, Rizk P, Muriel MP, Duyckaerts C, Oertel WH, Caille I, et al. Dopamine depletion impairs precursor cell proliferation in Parkinson disease. Nat Neurosci. 2004;7(7):726-35.

Horsfield MA, Jones DK. Applications of diffusion-weighted and diffusion tensor MRI to white matter diseases - a review. NMR Biomed. 2002;15(7-8):570-7.

Jones DK, Williams SC, Gasston D, Horsfield MA, Simmons A, Howard R. Isotropic resolution diffusion tensor imaging with whole brain acquisition in a clinically acceptable time. Hum Brain Mapp. 2002a;15(4):216-30.

Jones DK, Griffin LD, Alexander DC, Catani M, Horsfield MA, Howard R, et al. Spatial normalization and averaging of diffusion tensor MRI data sets. Neuroimage. 2002b;17(2):592-617.

Jones DK, Symms MR, Cercignani M, Howard RJ. The effect of filter size on VBM analyses of DT-MRI data. Neuroimage. 2005;26 (2):546-54.

Kates WR, Burnette CP, Jabs EW, Rutberg J, Murphy AM, Grados M, et al. Regional cortical white matter reductions in velocardiofacial syndrome: a volumetric MRI analysis. Biol Psychiatry. 2001;49(8):677-84

Kates WR, Antshel KM, Abdulsabur N, Colgan D, Funke B, Fremont $\mathrm{W}$, et al. A gender-moderated effect of a functional COMT polymorphism on prefrontal brain morphology and function in velo-cardio-facial syndrome (22q11.2 deletion syndrome). Am J Med Genet B Neuropsychiatr Genet. 2006;141B(3):274-80.

Kiehl TR, Chow EW, Mikulis DJ, George SR, Bassett AS. Neuropathologic features in adults with 22q11.2 deletion syndrome. Cereb Cortex. 2008.

Li J, Yu C, Li Y, Liu B, Liu Y, Shu N, et al. COMT val158met modulates association between brain white matter architecture and IQ. Am J Med Genet B Neuropsychiatr Genet. 2009;150B (3):375-80.

Makki MI, Chugani DC, Janisse J, Chugani HT. Characteristics of abnormal diffusivity in normal-appearing white matter investigated with diffusion tensor MR imaging in tuberous sclerosis complex. AJNR Am J Neuroradiol. 2007;28(9):1662-7.

Miller GA, Chapman JP. Misunderstanding analysis of covariance. J Abnorm Psychol. 2001;110(1):40-8.

Mitelman SA, Torosjan Y, Newmark RE, Schneiderman JS, Chu KW, Brickman AM, et al. Internal capsule, corpus callosum and long associative fibers in good and poor outcome schizophrenia: a 
diffusion tensor imaging survey. Schizophr Res. 2007;92(1-3): 211-24.

Mitnick RJ, Bello JA, Shprintzen RJ. Brain anomalies in velo-cardio-facial syndrome. Am J Med Genet. 1994;54(2):100-6.

Mori S, Zhang J. Principles of diffusion tensor imaging and its applications to basic neuroscience research. Neuron. 2006;51 (5):527-39.

Mori S, Wakana S, van Zijl PCM, Nagae-Poetscher LM. MRI atlas of human white matter. 2005.

Murphy KC. Schizophrenia and velo-cardio-facial syndrome. Lancet. 2002;359(9304):426-30.

Murphy KC, Owen MJ. Velo-cardio-facial syndrome: a model for understanding the genetics and pathogenesis of schizophrenia. $\mathrm{Br}$ J Psychiatry. 2001;179:397-402.

Murphy KC, Jones LA, Owen MJ. High rates of schizophrenia in adults with velo-cardio-facial syndrome. Arch Gen Psychiatry. 1999;56(10):940-5.

Nakamura M, McCarley RW, Kubicki M, Dickey CC, Niznikiewicz MA, Voglmaier MM, et al. Fronto-temporal disconnectivity in schizotypal personality disorder: a diffusion tensor imaging study. Biol Psychiatry. 2005;58(6):468-78.

Oskarsdottir S, Vujic M, Fasth A. Incidence and prevalence of the 22q11 deletion syndrome: a population-based study in Western Sweden. Arch Dis Child. 2004;89(2):148-51.

Pierpaoli C, Basser PJ. Toward a quantitative assessment of diffusion anisotropy. Magn Reson Med. 1996;36(6):893-906.

Poulton R, Caspi A, Moffitt TE, Cannon M, Murray R, Harrington H. Children's self-reported psychotic symptoms and adult schizophreniform disorder: a 15-year longitudinal study. Arch Gen Psychiatry. 2000;57(11):1053-8.

Robin NH, Taylor CJ, McDonald-McGinn DM, Zackai EH, Bingham $\mathrm{P}$, Collins KJ, et al. Polymicrogyria and deletion 22q11.2 syndrome: window to the etiology of a common cortical malformation. Am J Med Genet A. 2006;140(22):2416-25.

Rugg-Gunn FJ, Symms MR, Barker GJ, Greenwood R, Duncan JS. Diffusion imaging shows abnormalities after blunt head trauma when conventional magnetic resonance imaging is normal. J Neurol Neurosurg Psychiatry. 2001;70(4):530-3.

Siever LJ, Davis KL. The pathophysiology of schizophrenia disorders: perspectives from the spectrum. Am J Psychiatry. 2004;161 (3):398-413.
Simon TJ, Ding L, Bish JP, McDonald-McGinn DM, Zackai EH, Gee J. Volumetric, connective, and morphologic changes in the brains of children with chromosome 22q11.2 deletion syndrome: an integrative study. Neuroimage. 2005;25(1):169-80.

Swillen A, Vandeputte L, Cracco J, Maes B, Ghesquiere P, Devriendt $\mathrm{K}$, et al. Neuropsychological, learning and psychosocial profile of primary school aged children with the velo-cardio-facial syndrome (22q11 deletion): evidence for a nonverbal learning disability? Child Neuropsychol. 1999;5(4):230-41.

Talairach J, Tournoux P. Co-planar stereotaxic atlas of the human brain. New York: Thieme; 1988.

Trivedi R, Gupta RK, Hasan KM, Hou P, Prasad KN, Narayana PA. Diffusion tensor imaging in polymicrogyria: a report of three cases. Neuroradiology. 2006;48(6):422-7.

Tunbridge EM, Bannerman DM, Sharp T, Harrison PJ. Catechol-omethyltransferase inhibition improves set-shifting performance and elevates stimulated dopamine release in the rat prefrontal cortex. J Neurosci. 2004;24(23):5331-5.

van Amelsvoort T, Daly E, Robertson D, Suckling J, Ng V, Critchley $\mathrm{H}$, et al. Structural brain abnormalities associated with deletion at chromosome 22q11: quantitative neuroimaging study of adults with velo-cardio-facial syndrome. Br J Psychiatry. 2001;178: 412-9.

van Amelsvoort T, Daly E, Henry J, Robertson D, Ng V, Owen M, et al. Brain anatomy in adults with velocardiofacial syndrome with and without schizophrenia: preliminary results of a structural magnetic resonance imaging study. Arch Gen Psychiatry. 2004;61(11):1085-96.

van Amelsvoort T, Zinkstok J, Figee M, Daly E, Morris R, Owen MJ, et al. Effects of a functional COMT polymorphism on brain anatomy and cognitive function in adults with velo-cardio-facial syndrome. Psychol Med. 2008;38(1):89-100.

Wechsler D. Wechsler intelligence scales for children. 3rd edn. San Antonio; 1991.

Wieshmann UC, Clark CA, Symms MR, Franconi F, Barker GJ, Shorvon SD. Reduced anisotropy of water diffusion in structural cerebral abnormalities demonstrated with diffusion tensor imaging. Magn Reson Imaging. 1999;17(9):1269-74.

Zinkstok J, Schmitz N, van Amelsvoort T, de Win M, van den Brink $\mathrm{W}$, Baas F, et al. The COMT val158met polymorphism and brain morphometry in healthy young adults. Neurosci Lett. 2006;405 (1-2):34-9. 